NOTICE: this is the author's version of a work that was accepted for publication in Information \& Management. Changes resulting from the publishing process, such as peer review, editing, corrections, structural formatting, and other quality control mechanisms may not be reflected in this document. Changes may have been made to this work since it was submitted for publication. A definitive version was subsequently published in Information \& Management, Vol. 51, no. 6 (2014). DOI: 10.1016/j.im.2014.01.002 
Myers, Michael D. and John R. Venable, "A Set of Ethical Principles for Design Science Research in Information Systems", Information \& Management, Special issue on IS Ethics: Past, Present and Future, Vol. 51, No. 6 (September 2014), pp. 801-809, available online at http://dx.doi.org/10.1016/j.im.2014.01.002.

\title{
A SET OF ETHICAL PRINCIPLES FOR DESIGN SCIENCE RESEARCH IN INFORMATION SYSTEMS
}

\author{
Michael Myers \\ Auckland University, Auckland, New Zealand \\ m.myers@auckland.ac.nz \\ John R. Venable \\ Curtin University, Perth, Western Australia, Australia \\ j.venable@curtin.edu.au
}

\begin{abstract}
Over the past decade design science research (DSR) has re-emerged as an important research paradigm in information systems. However, the current recommended approaches to conducting design science research do not consider ethics. Hence the purpose of this paper is to begin a debate about the need for ethical principles in DSR in IS. In order to start this debate we suggest a set of ethical principles for DSR in IS. While the interpretation and application of the principles might not always be straightforward, our argument is that all design science researchers in IS should give some consideration to ethics.
\end{abstract}

\section{Introduction}

In recent years design science research (DSR) [1-3] has re-emerged as an important research paradigm in the information systems field. One indication of this is the appointment of design science researchers as editors of IS journals such as MIS Quarterly (Paolo Goes), Journal of the AIS (Shirley Gregor), Communications of the AIS (Matti Rossi), and Journal of Information Technology Theory and Application (Marcus Rothenberger).

Venable and Baskerville [4] define Design Science Research as "Research that invents a new purposeful artefact to address a generalised type of problem and evaluates its utility for solving problems of that type" (p. 142). Unlike the social science or behavioural science paradigms that had come to dominate IS research - where the main objective of the researcher is to understand the world - DSR builds on the engineering tradition of research in which the whole idea is to invent new technologies or artefacts that can be used as ways to change (and hopefully improve) the world. Design science researchers create new artefacts (e.g. new software, processes, and systems) that are intended to improve the effectiveness or efficiency of an organisation, [1] to improve people's health, education or quality of life [5, 6], and to improve community interaction and well-being [7]. Hence the explicit purpose of DSR is to create new artefacts and knowledge about them whereby people can change and improve the world in which we live.

Over the past decade a rich literature in design science research in IS has developed. Many processes and methods for conducting DSR have been proposed, from the simple "buildevaluate" cycle $[1,2]$ to more elaborate linear processes (with feedback loops) $[3,8]$, flexible processes [9], methods supporting participation and researcher-user interaction [7, 10, 11], and methods combining DSR with Action Research [10, 12]. Several works have developed and debated the content and form of design theories, as formalisations of the knowledge 
created in DSR [13-19]. The most seminal work though, which can be credited with reinvigorating DSR in IS, is that by Hevner et al [1]. This article suggests guidelines for conducting DSR and has become one of the most cited papers in the IS field.

However, we believe there is one notable omission in all of the current recommended approaches to conducting design science research. The guidelines and methods proposed so far focus on the viability, efficiency, and effectiveness of the artefact, but they do not include any consideration of ethics. In other words, the current guidelines simply assume that efficiency and effectiveness are always "good" and that the design science researcher knows what is best for improving business or society. But what if people disagree about what is "good"? What if the artefact improves the effectiveness and efficiency of spying on all citizens? We suggest that the lack of any ethical guidelines for design science researchers in information systems could lead to problems in the future, and could potentially harm the reputation of the IS field as a whole. We believe that the lack of any ethical guidelines is a significant omission in the contemporary theory and practice of design science research in information systems.

Hence this paper is intended to begin a dialog and debate about the need for ethical principles in DSR in information systems. To begin this debate we suggest a set of ethical principles for DSR, although we wish to emphasize the tentative nature of our principles at this stage.

\section{Motivation and Purpose}

Ethics can be defined as 'the moral principles governing or influencing conduct' or 'the branch of knowledge concerned with moral principles' [20]. We suggest there are at least four reasons why ethical principles should be considered by design science researchers: (1) the dual potential of IT; (2) the increased focus on the teaching of ethics in business schools; (3) the increased focus by institutional review boards on the ethical principles that need to be followed in research projects and (4) the different ethical priorities that design science researchers should have as compared with behavioural researchers in IS.

First, in his seminal article written almost 30 years ago, Mason [21] pointed out the dual potential of information technology. Mason showed that IT can be used to enhance or to destroy human dignity. IT can improve people's lives, but it also has the potential to make them much worse. For example, IT can be used to improve patient outcomes in medicine, but the increased surveillance capabilities of IT can seriously threaten privacy. Given this dual potential of IT, Mason argued that IS scholars have a responsibility to ensure that information systems are used in the right way. He said "We must assume some responsibility for the social contract that emerges from the systems that we design and implement" and make sure that IT is used "to create the kind of world in which we wish to live" [21].

Second, following the scandals associated with the global financial crisis, almost all business school deans and faculty recognize the increased importance of ethics. The Bloomberg Business Week ranking of the best undergraduate business schools, for example, now includes a section in the online survey given to students asking them to rank their program's ethics offerings [22]. Business school accrediting bodies such as AACSB and EQUIS also look for a focus on ethics in the curriculum. Since most design science researchers in IS are located in business schools, we suggest this is another reason for ethical principles to be considered when designing IT artefacts. 
Third, most universities and research institutions nowadays require researchers to obtain permission from their own institutional review board or human subjects' ethics committee if they are intending to conduct any research project that involves real people. Many academic and professional associations, including those relevant to IS researchers, have ethical codes that members are required to follow. For example, the ethical code for the Academy of Management includes 'enforced standards' that all individuals must adhere to if they are carrying out the work of the academy [23]. The code of research conduct for the Association for Information Systems (AIS) includes items that are mandatory for all members of AIS to follow, and guidelines that are "recommended ethical behaviour" [24].

Fourth, the ethical priorities for design science researchers need to be different from those of behavioural researchers in IS. As a general rule, social science and behavioural researchers in most disciplines give priority to the people being studied. For example, the ethical guidelines for the American Anthropological Association say the following:

Anthropologists must weigh competing ethical obligations to research participants, students, professional colleagues, employers and funders, among others, while recognizing that obligations to research participants are usually primary (our emphasis). In doing so, obligations to vulnerable populations are particularly important.[25]

If there are competing ethical obligations to various stakeholders, anthropologists, like most other social and behavioural researchers, are supposed to give priority to the people being studied. However, researchers in engineering and computer science do not give priority to the people being studied; rather, the most important ethical obligation of an engineer is to the public. The first principle in the Code of Conduct for members of the British Computer Society, for example, is about the "public interest"[4]. The ACM Code of Ethics is similar, the very first principle stating that an ACM member must contribute to society and human well-being. The first principle in the ACM code says the following:

This principle concerning the quality of life of all people affirms an obligation to protect fundamental human rights and to respect the diversity of all cultures. An essential aim of computing professionals is to minimize negative consequences of computing systems, including threats to health and safety. When designing or implementing systems, computing professionals must attempt to ensure that the products of their efforts will be used in socially responsible ways, will meet social needs, and will avoid harmful effects to health and welfare.[26]

Given that the artefacts developed by design science researchers may be used long after the research project has finished and by people who were not involved at the time (the wider public), the ethical principles and the priority of these principles in DSR need to be significantly different from those oriented towards social science and behavioural researchers in IS. If there is conflict between principles, most computing and engineering professional bodies say that the public interest should take priority over the responsibility to the people or organization being studied. We believe this applies equally to design science researchers in IS.

Given these four reasons, we believe it is important for all design science researchers in IS to consider the ethical dimensions of the artefacts they are creating. Do we want to leave the world in a better or a worse state at the end of our research project? As IS researchers, do we 
want to have a reputation for integrity and competence, or one for the use of questionable practices? This last statement may seem somewhat extreme, but it is clear that the reputation of the accounting profession was affected by the collapse of Enron. Carnegie and Napier point out that, after the Enron scandal, public confidence in the accounting profession was significantly undermined [27]. With concerns raised about the accounting profession's integrity and competence, governments all around the world ended up legislating for the enforcement of certain ethical standards by accountants.

Hence the purpose of this paper is to suggest a set of ethical principles for design science research in information systems. Our argument is that all design science researchers in IS should consider the ethical dimensions of the artefacts they are creating. We should be proactive and agree on a set of ethical principles for DSR ourselves, and not wait until there is some kind of public event that threatens our reputation. This paper is an attempt to begin a debate on what these ethical principles might be.

The paper is organised as follows. In Section 2 we review some of the literature immediately relevant to the development of ethical principles for the conduct of design science research (DSR) in information systems. In Section 3 we propose a set of ethical principles for the conduct of DSR in IS. In Section 4 we provide a few examples of how the ethical principles can be applied. Section 5 is the discussion and conclusions.

\section{Literature Relevant to Ethical Principles for DSR}

Some IS researchers have already suggested that ethics should be considered in our research work. For example, Myers and Klein developed a set of principles for critical research in information systems, one principle being that of ethics [28]. Venable et al advocated design and diffusion of "Systems for Human Benefit" in IS [5, 6]. Similarly, Heusigner argued that design science researchers in IS should pay more attention to critical and emancipatory research projects i.e. those that aim to achieve a better world by removing inequalities [29]. Siek discusses the ethical responsibilities for those that design sociotechnical health interventions [30]. Myers and Miller suggested Aristotle's ethics as a way of conceptualizing the ethical dilemmas in the use of information technology [31]. Venable conducted a Critical Systems Heuristics analysis of different stakeholder interests in Design Science Research, which suggested some potential ethical principles for DSR [32]

There are many important ethical principles that could apply to research. For example, one of the most fundamental ethical principles is that of the golden rule [33]. The golden rule states that you should do unto others as you would have them do unto you. Applied to research, this means that if you are unsure about the ethics of a particular action on your part, then it is a good idea to put yourself into the other person's shoes [34].

A similar principle is "do no harm", which is the key principle of the Hippocratic Oath for doctors, the first principle of the Statement on Ethics of the American Anthropological Association [25], and Google's motto. An application of this principle to DSR would be to say that all researchers need to consider the potential victims of a new technology and their needs. There are risks that after the development of a new technology it might be misunderstood and misused, possibly with disastrous consequences.

Although we could cast our net more widely to consider ethical principles from the philosophical literature in general, for our purposes we consider it fruitful to derive our suggested ethical principles for design science research from a more limited set of sources. 
These sources are those that are closely related to the scholarly endeavour pursued by IS researchers. Hence articles that discuss ethical issues or principles in relation to information and computing technology are clearly relevant for our purpose, as are those that discuss ethical issues in relation to the conduct of research and more specifically, research related to the creation of artefacts. Based on these selection criteria, we consider that four sources are particularly relevant.

First, the four ethical issues for the information age identified by Mason are particularly relevant to the design of information systems [21]. Second, the ethical principles that are considered by institutional review boards are relevant for any research projects that involve human subjects. Third, since artefacts developed in DSR are often software, the Association of Computing Machinery (ACM) Software Engineering Code of Ethics and Professional Practice is particularly relevant, although many parts of the code are equally relevant for other kinds of artefacts [26, 35]. Finally, Venable makes an analysis of DSR stakeholders that partially addresses the lack of ethical principles for DSR and encourages DSR be undertaken from a more critical perspective [32]. Since design science research involves the creation of IT artefacts for research, and these artefacts are explicitly designed for people and organisations, we believe that a combination of ethical principles from all these sources is at least a reasonable starting point for the development of ethical principles for IS researchers. We now review each of these four sources in turn.

\section{Mason's Ethical Principles}

The four ethical issues identified by Mason are privacy, accuracy, property and accessibility [21]. Privacy concerns what information about one's self a person must reveal to others, under what conditions and with what safeguards. Accuracy refers to who is responsible for the authenticity, fidelity, and accuracy of the information. Property relates to the ownership of information. Accessibility concerns what rights a person or organisation has to information and what safeguards there are. Some of the ethical questions that emerge from a consideration of these four issues identified by Mason [21] are summarized in Table 1 below.

Table 1

\begin{tabular}{ll}
\hline Ethical issue & Questions for design science researchers \\
\hline Privacy & $\begin{array}{l}\text { Does the proposed new system threaten privacy in any way? What } \\
\text { safeguards are in place to protect privacy? Who is responsible for } \\
\text { protecting privacy? }\end{array}$ \\
Accuracy & $\begin{array}{l}\text { Is the information being gathered accurate? Who is responsible for } \\
\text { ensuring accuracy? }\end{array}$ \\
Property & Who owns the intellectual property rights for the artefact? Who \\
Access & Owns the information being collected? \\
& Who can access the information gathered by the system? Who has \\
& access privileges? Are some kinds of people going to be excluded? \\
& Who is responsible for ensuring that the right people have the right \\
& access?
\end{tabular}

\section{Ethical Principles Used by Institutional Review Boards}

Institutional review boards (IRBs) focus on those ethical principles that apply to the conduct of research involving human (and animal) subjects. The ethical principles that are usually taken into consideration are described below (see also [33]). 
The first principle is that of honesty. It is fundamental to all research that researchers are honest in reporting their research findings and in describing their research method. The fabrication of evidence is unethical. This principle applies especially to DSR in that there is a tendency for design science researchers to overstate the importance of the new technology they have invented and its contribution to academic research. Oates [36] makes a similar point about action research, which like DSR involves an attempt to change the world for the better. Oates says that action researchers, perhaps subconsciously, want to show that the exercise is useful, and that their theory or method is valid. She calls this phenomenon 'selfdelusion and group-think' and recommends the use of a 'devil's advocate' procedure to guard against this. We think the idea of using some kind of devil's advocate procedure would also be relevant for DSR. Part of this procedure could be trying to think of possible side effects of the new invention and envisaging any possible harm.

The second principle is that a researcher should not plagiarize. This principle is often considered to be one of the most important for academics and is enshrined in the AIS Code of Conduct. The key idea is that a researcher should not present someone else's work as their own, and should appropriately acknowledge the work of others. This principle is somewhat similar to Mason's ethical issue related to property.

The third principle is that of informed consent. Informed consent means that the human subjects involved with a particular research project should, as far as possible, 'be enabled freely to give their informed consent to participate, and advised that they can terminate their involvement for any reason, at any time' [37]. Of course it might be unrealistic to expect that you can obtain the consent of everyone, but it should be possible if you are simply testing a prototype. Most DSR projects involve a proof-of-concept with a small number of users, and hence obtaining informed consent should be considered mandatory in almost all cases.

The fourth principle is that of permission to publish. In social research this principle requires the researcher to ask permission from an appropriate person in an organisation, if most of the data being collected is from that organisation. This is simply a common courtesy to those that might have provided substantial support and help to the research project. Hence, if the artefact has been developed in conjunction with an organisation, a suitable representative organisation should be consulted before any publication that is written about the artefact. This consultation assumes, of course, that any issues related to intellectual property have been resolved beforehand.

The principles embedded in institutional review boards described above are by and large rooted in the natural and especially behavioural sciences, which as was noted earlier focus on understanding the world as it is and do not focus on creating new artefacts. While the above principles are relevant to DSR (especially to evaluation in DSR), the creation of new artefact(s) introduces new ethical concerns. We next turn our attention to the ACM/IEEE-CS Software Engineering Code of Ethics and Practice for inspiration on how to address artefactrelated ethical issues.

\section{ACM/IEEE-CS Software Engineering Code of Ethics and Practice}

The ACM/IEEE-CS Software Engineering Code of Ethics and Practice (SE Code) [26, 35] addresses many areas relevant to DSR, especially if the artefact (or one of the artefacts) developed is software. Even if no software is developed, many of the principles apply to any kind of artefact (e.g. methods, techniques, models, tools, or other kinds of physical artefacts). At its highest level, the SE Code incorporates eight principles as described below. Moreover, 
besides the principles, the code also states the rationale for its design. Part of that rationale states that:

These Principles should influence software engineers to consider broadly who is affected by their work; to examine if they and their colleagues are treating other human beings with due respect; to consider how the public, if reasonably well informed, would view their decisions; to analyze how the least empowered will be affected by their decisions; and to consider whether their acts would be judged worthy of the ideal professional working as a software engineer. In all these judgments concern for the health, safety and welfare of the public is primary; that is, the "Public Interest" is central to this Code. [26].

This rationale can reasonably be applied to DSR. The eight principles in the SE code are as follows:

1. PUBLIC - Software engineers shall act consistently with the public interest.

2. CLIENT AND EMPLOYER - Software engineers shall act in a manner that is in the best interests of their client and employer consistent with the public interest.

3. PRODUCT - Software engineers shall ensure that their products and related modifications meet the highest professional standards possible.

4. JUDGMENT - Software engineers shall maintain integrity and independence in their professional judgment.

5. MANAGEMENT - Software engineering managers and leaders shall subscribe to and promote an ethical approach to the management of software development and maintenance.

6. PROFESSION - Software engineers shall advance the integrity and reputation of the profession consistent with the public interest.

7. COLLEAGUES - Software engineers shall be fair to and supportive of their colleagues.

8. SELF - Software engineers shall participate in lifelong learning regarding the practice of their profession and shall promote an ethical approach to the practice of the profession.[26]

Principles 1, 2, 5, 6, and 8 above are particularly relevant. Principles 1, 2, and 6 all affirm the primacy of meeting the public interest, even potentially at the expense of the client, their own organisation, or even themselves. Principles 5 and 8 both affirm the practice and promotion of ethical behaviours.

Each of the above principles is expanded in the SE Code with sub-principles. Several subprinciples from the SE Code are particularly of interest. In terms of DSR, when reading the principles below (in conjunction with those above), one can replace "the software engineer" with "the DSR researcher", "software" with "the artefact(s)", and "the client" with "the public" (although some forms of DSR have a client as well). For example, consider the following sub-principles:

1.02. Moderate the interests of the software engineer, the employer, the client and the users with the public good.

1.03. Approve software only if they have a well-founded belief that it is safe, meets specifications, passes appropriate tests, and does not diminish quality of life, diminish 
privacy or harm the environment. The ultimate effect of the work should be to the public good.

1.04. Disclose to appropriate persons or authorities any actual or potential danger to the user, the public, or the environment, that they reasonably believe to be associated with software or related documents.

1.05. Cooperate in efforts to address matters of grave public concern caused by software, its installation, maintenance, support or documentation.

1.06. Be fair and avoid deception in all statements, particularly public ones, concerning software or related documents, methods and tools.

1.07. Consider issues of physical disabilities, allocation of resources, economic disadvantage and other factors that can diminish access to the benefits of software... 2.07. Identify, document, and report significant issues of social concern, of which they are aware, in software or related documents, to the employer or the client... 3.03. Identify, define and address ethical, economic, cultural, legal and environmental issues related to work projects...

4.01. Temper all technical judgments by the need to support and maintain human values...

5.01 Ensure good management for any project on which they work, including effective procedures for promotion of quality and reduction of risk...

5.09. Ensure that there is a fair agreement concerning ownership of any software, processes, research, writing, or other intellectual property to which a software engineer has contributed...

6.05. Not promote their own interest at the expense of the profession, client or employer...

6.07. Be accurate in stating the characteristics of software on which they work, avoiding not only false claims but also claims that might reasonably be supposed to be speculative, vacuous, deceptive, misleading, or doubtful...

6.08. Take responsibility for detecting, correcting, and reporting errors in software and associated documents on which they work...

7.03. Credit fully the work of others and refrain from taking undue credit...

8.01. Further their knowledge of developments in the analysis, specification, design, development, maintenance and testing of software and related documents, together with the management of the development process." [26]

As can be seen, the SE Code identifies a number of areas potentially relevant to ethical issues or principles in DSR, including (1) serving the needs of the public, (2) ensuring the quality of the artefact, (3) making truthful (not overstating) claims about the artefact's utility or fitness for purpose, (4) appropriately sharing credit for the research work, and (5) reporting ethical violations to proper authorities, especially where risks to the public are not being addressed.

Clearly the major lesson from the ACM code is that DSR in IS should primarily serve the needs of the public; most of the principles and sub-principles follow from this fundamental principle. However, it is not clear from the ACM code how one should determine the public interest. Venable partially addresses this in his work as described below.

\section{Venable's Critical Systems Heuristic Analysis of DSR}

Venable applied the Critical Systems Heuristic (CSH) framework [38] to DSR. CSH is used to determine boundary conditions of whose and which interests are relevant to determining the requirements and needs for a system (or for an artefact to be developed in DSR). 
The CSH framework, developed by Ulrich, identified four different kinds of stakeholders, namely Clients, Professionals, Decision Makers, and Witnesses. Clients are those people are involved and who benefit (or suffer) from the system once built and put into operation. Professionals are those who do the requirements analysis, design, development etc. Decision Makers are those who decide whether to fund, support, and implement the system (artefact) or not. Witnesses are those who witness for the needs and interests of those who are not involved or cannot be involved, such as children or future generations, but also other kinds of less-empowered people who are otherwise inhibited from participating and representing their own interests. [38]

Venable applied CSH to DSR [32]. He noted that in DSR, the clients are often in some way abstract, their interests being derived from the literature on business or organisational problems (although ADR and other DSR-oriented forms of Action Research directly engage a client). The professionals are the DSR researchers. The Decision Makers may be funding bodies, the DSR researchers themselves if their research is self-funded within their selfdecided workload, or an organisation that may assign DSR research tasks to its employees. Finally, witnesses are also potentially very abstract, in that the artefact(s) developed may be applied in many different future situations, which may be very hard to predict. The people to be witnessed for could potentially be anyone in the public or humanity at large.

This fourth group to be witnessed for corresponds directly to the public in the SE Code. But as one cannot reasonably address all of humanity, whose interests should be witnessed for and by whom and how? Venable points out that "The question is one of expertise and ability, but also of legitimacy." [32, p. 108] Venable suggests six alternative potential ways for representing outside (non-client) interests:

1. The DSR researcher may represent them by himself/herself

2. A community of experts

3. Rigorous naturalistic evaluation $[9,39]$

4. DSR-oriented Action Research (with real, not abstract clients)

5. Government

6. Direct involvement by the public

However, we would critique the third and fourth points above in that naturalistic evaluation (use of the real system by real users for real purposes) potentially places people at risk (indeed so might some forms of artificial evaluation) and even with real clients in DSRoriented forms of Action Research, there is no guarantee that other, non-client (e.g. public) interests will be identified and addressed.

Venable further highlights that the DSR researcher needs to make a practical choice from among the above six possibilities as well as design practical ways to implement that choice. He notes that "the cost and resources used [for witnessing] must be balanced against the need and risk" [32, p. 109]. To do so, potential stakeholders must be identified, risks must be estimated, and the feasibility and costs of different approaches for witnessing for noninvolved stakeholders estimated [32].

\section{Summary}

We have identified four potential sources for the development of a set of ethical principles for design science research in IS. We acknowledge that there are many other sources that we could have used, and we are certainly not suggesting that these four are necessarily the best or only ones that could be used. However, we believe that the four sources we have identified 
are relevant to our purpose (as explained earlier), and represent at least a starting point in the debate about ethical principles for DSR in information systems. We also acknowledge that all four sources have their weaknesses. For example, Principle 1 of the ACM/IEEE-CS Software Engineering Code of Ethics and Practice says that the public interest should come first, but determining what is in the public interest is not always obvious. In fact, there may be genuine disagreements and debate about the public interest. Venable's application of critical systems heuristics is also not straightforward, since following one point in the framework may compromise another and put people at risk. The next section attempts to integrate these four sources into a coherent set of ethical principles for DSR.

\section{Ethical principles for design science research}

Based on our literature review and the sources we have identified, this section derives a set of ethical principles for the conduct of DSR in IS. We can consider that the four ethical principles for research on human subjects usually taken into account by institutional review boards (honesty, not plagiarising, informed consent of research participants, and permission to publish), even though aimed generally at behavioural rather than design science research, are still relevant to DSR. Mason's four ethical issues for the design of information systems (privacy, accuracy, property, and access) bring out issues specific to information systems (a particular kind of artefact), which are closely related to those of the SE Code (software is a closely related kind of artefact). Mason's property principle is closely related to not plagiarising and to the SE Code regarding the need to fairly apportion ownership of the intellectual property appropriately, both in terms of the credit and any monetary return ( $c f$. SE Code principles 5.09 and 7.03 above). Mason's principles for privacy, accuracy, and access all relate to the needs of the client as well as to the needs of the public (particularly access for the public). The SE Code also emphasises the need to protect the interests of the public (principles 1,2, and 6) and the need to ensure the quality of developed software (principle 3), or in DSR, a developed artefact, whether software or not. Venable focused on the protection of the interests of the public through the practice of witnessing for their interests, which requires identifying stakeholders, assessing risks to them (possibly through involving them), and selecting an appropriate way to faithfully represent their interests in the DSR process.

Based on all the above principles, we believe it is possible to synthesise them into a proposed a set of ethical principles for design science research in information systems. We would like to emphasize, however, the tentative nature of our suggested set of principles. They are a suggested set, from a diverse range of sources, and it is possible that we may have missed some principles from the extensive philosophical literature on ethics. Not all principles may apply to every DSR project. Also, the principles cannot be applied mechanistically; researchers need to give thoughtful consideration as to whether and how they should be taken into account in a particular research project. Nevertheless, we believe that some ethical principles are better than none at all. We are providing our suggested set of principles simply as a means of starting the debate. Our suggested set of six ethical principles for DSR are summarized in Table 2. 


\begin{tabular}{|c|c|c|}
\hline \multicolumn{3}{|c|}{ Ethical Principle } \\
\hline & $\begin{array}{l}\text { The Public } \\
\text { Interest }\end{array}$ & $\begin{array}{l}\text { Design science researchers should explicitly identify all } \\
\text { stakeholders who may be affected by the artefacts once placed } \\
\text { into use and critically consider what benefit or harm may } \\
\text { result for/to them. Generally, principles of safety, health, } \\
\text { democracy, empowerment, and emancipation for all, } \\
\text { especially the public, should dominate in choices of features } \\
\text { and capabilities that an artefact should have or should not } \\
\text { have. }\end{array}$ \\
\hline 2. & $\begin{array}{l}\text { Informed } \\
\text { Consent }\end{array}$ & $\begin{array}{l}\text { All design science researchers in IS should obtain informed } \\
\text { consent from any person who is in some way involved with } \\
\text { the research project. }\end{array}$ \\
\hline 3. & Privacy & $\begin{array}{l}\text { All design science researchers in IS should ensure that there } \\
\text { are adequate safeguards in place to protect privacy, not just of } \\
\text { those people directly involved with the current project (as } \\
\text { with any behavioural research project), but those who might } \\
\text { use or be affected by any developed software, IS, or IS } \\
\text { development method artefact in the future. }\end{array}$ \\
\hline 4. & $\begin{array}{l}\text { Honesty and } \\
\text { Accuracy }\end{array}$ & $\begin{array}{l}\text { Design science researchers should not plagiarize ideas but } \\
\text { should acknowledge inspiration from other sources. They } \\
\text { should also honestly report their research findings about the } \\
\text { new artefact. }\end{array}$ \\
\hline 5. & Property & $\begin{array}{l}\text { All design science researchers in IS should ensure that there is } \\
\text { an agreement about ownership of the IP right at the start of the } \\
\text { project. There should also be an agreement about the } \\
\text { ownership of any information that is collected during the } \\
\text { project and what rights the researcher has to publish the } \\
\text { findings. }\end{array}$ \\
\hline 6. & $\begin{array}{l}\text { Quality of } \\
\text { the Artefact }\end{array}$ & $\begin{array}{l}\text { Every attempt should be made to ensure the quality of the } \\
\text { artefact(s). Where risks are potentially high, for example in } \\
\text { safety critical situations, design should account for and } \\
\text { address such risks and evaluation and testing should be } \\
\text { sufficiently rigorous to ensure safety in use. }\end{array}$ \\
\hline
\end{tabular}

We believe that the six ethical principles for design science research suggested above take account of the fact that the IS researcher conducting DSR almost always conducts research with and for people using IT, but also that other kinds of artefacts may be designed that are not directly IT-related. The principles also recognize that if the artefact ends up being used after the research project has finished, it may be used by the public at large, and in which case the public interest should always have priority.

The first principle suggests that design science researchers should explicitly identify all stakeholders who may be affected by the artefacts, but the public interest should come first. Depending on the severity of the potential risks and consequences and the ability to understand the needs of stakeholders who cannot represent their own interests, an appropriate way to faithfully witness for these other stakeholders should be decided and implemented. Within that method, efforts should be made to realistically balance the needs of the researcher, client, and users with those in the public who may be affected. Clearly no significant harm should occur to members of the public unless such harm is balanced against 
significant benefits to others, including the public. Two key aspects to consider for software are information privacy (principle 2) and who will and who will not have access privileges to the new system both now and in the future.

The second principle is focused more on those who are directly involved with the research project, and is similar to the ethical principles for all other kinds of research. Informed consent means informing people of their rights and any risks that might be involved with their participation. This is particularly important for the evaluation component of research, which may involve human participants as experimental subjects.

The third principle recognizes that one of the distinguishing features of software artefacts and IT more generally is that it can threaten privacy if adequate safeguards are not put in place.

The fourth and fifth principles concerning honesty and accuracy incorporate ethical principles that are similar for many other kinds of research. Claims concerning the significance of the problem addressed and the artefact's relevance to practice must not be overstated. Similarly, claims for the utility of the artefact as well as the lack or seriousness of any side effects caused by the artefact should not be overstated, according to the rigour of the conducted evaluation. Researchers should ensure that there are appropriate procedures in place to verify the accuracy of any data collected.

The sixth principle is derived from the ACM code of ethics for computer scientists and software engineers. The principle applies not just to software but also to any documentation about the artefact. The artefact should substantially work as advertised, be tested as thoroughly and rigorously as practical, and be as easy to understand, learn and use as is appropriate. It should also be difficult to misuse or be unlikely to be misused in ways that disadvantage people or otherwise cause harm, and be extremely unlikely to fail in any serious or dangerous way. The need for quality should be based on an assessment of potential risks to the public should problems of misuse or artefact/system failure occur. Artefacts that are safety critical or may have serious consequences must meet very high standards of design, implementation, and testing.

Having identified a set of ethical principles for the conduct of design science research, we need to emphasize once again that these are a suggested set. The principles are derived from a diverse range of sources, but additional sources could have been used. Also, the interpretation and application of the principles is not necessarily straightforward. For example, who decides what is in the public interest? Is it in the public interest to create software that has the potential to prevent terrorist attacks, but yet threatens privacy? On the one hand such software might be in the public interest because it is designed to promote health and safety, but on the other it might be against the public interest because it subjects them to constant surveillance. Such a scenario illustrates that, not only is the interpretation of each principle potentially problematic, but there may be conflict between some of the principles. For example, Principle 1 (the public interest) might conflict with Principle 3 (privacy). Deciding which principle takes priority in a particular situation is one that requires careful thought.

Another question that needs to be considered is when to apply the principles. Our suggestion is that one needs to consider ethical issues and the application of these principles very early in the research process, before any research activities that may impact on people are conducted. Typically this would be at the problem formulation or equivalent stage of the DSR research - 
before an artefact is built. However, researchers should retain an awareness of ethical issues throughout the research project.

To illustrate the usefulness of the above principles - and describe some of the ethical dilemmas that might arise - the next section describes their application to two different DSR studies from the literature.

\section{Examples}

This section illustrates the usefulness of our suggested principles by describing their application to two different DSR studies from the literature. Analysing their application will highlight important issues as well as provide some justification for their relevance to and appropriateness for the conduct of DSR.

Design Science Research can be conducted in two fundamentally different ways. First, it can be conducted in a way that is heavily engaged with one or more clients (organisations or people), such as is advocated by the Action Design Research (ADR) [10] or Participatory Action Design Research (PADR) [7] methodologies. Such engagement encourages development and evaluation in close collaboration with the client(s). This leads to richer and more relevant requirements for improvement, but can also potentially place the clients at risk and also naturally leads to emphasising their interests. A second approach is without a specific client, in which understandings of the requirements are gleaned from the literature and the development and evaluation of the artefact are conducted at arm's length from any potential users. In the remainder of this section, we will discuss two examples, first an example of DSR conducted in a highly engaged way, and second, an example of DSR that is conducted at arm's length.

\section{Example 1 - Action Design Research (ADR)}

The ADR method [10] includes a problem formulation stage, during which one determines the problem to be solved from the participants in the research. Emphasis is also given to "securing long-term commitment" and "a client-researcher agreement", which address principles 2 (Informed Consent) and 5 (Property, particularly intellectual property). However, ADR does not focus on determining who all the stakeholders are, does not seek to identify who could be disadvantaged or become victims of the technology, nor does it include any provision for witnessing for the interests of those who could be disadvantaged.

Sein et al [10] report on the development of a new form of competence management system (CMS) at Volvo using ADR. Their study reveals that there was strong engagement with a good, balanced group of stakeholders - including all those likely to be affected. In particular, the research engaged participation from three stakeholder groups: the Web Program Center, the HR department, and knowledge workers. The knowledge workers are those who would be most likely to be negatively affected by the new CMS. Thus, in this case study, potentially disaffected stakeholders were able to witness for themselves. The end result was that the interests and issues of knowledge workers were raised and dealt with through revising design principles and features of the CMS to accommodate the needs and preferences of the knowledge workers that would use the CMS. Thus the case reported in Sein et al [10] meets our proposed ethical principle 1 concerning the public interest.

However, we should also consider that, lacking specific advice in ADR to identify and witness for potentially adversely affected stakeholders, it may have just been lucky or serendipitous that knowledge workers could represent their own interests in the example case 
study. One can imagine that in locations without such participative development and decision making traditions as in Scandinavia, employees, customers, and other people potentially affected by the software might not be witnessed for.

We acknowledge that the use of action design research to develop a CMS in this particular case study was generally quite low risk and largely uncontroversial, but one can imagine other kinds of DSR developed artefacts with potentially much more serious consequences, such as discussed in the next example.

\section{Example 2 - Network Science and Weapons of Mass Destruction}

The second example that we will consider involves DSR where there was no strong link to a client; instead the problem was drawn from the literature. The problem to be addressed by the research proposed in Peiris et al [40] was how to reduce proliferation of weapons of mass destruction (WMDs, e.g. nuclear weapons), particularly to keep them out of the hands of terrorists. The approach proposed was to develop a new way to analyse intelligence data using Network Science techniques, in order to determine key vulnerabilities that could be disrupted in order to weaken or disable a network attempting to create WMDs. The data to be analysed included data about people, resources, knowledge, locations, relationships between people, and other information about necessary steps required to create weapons of mass destruction. Clearly, preventing or inhibiting WMDs from getting into the hands of terrorists would be very valuable and a significant research contribution.

The planned research was to be conducted by a PhD student. The student's research proposal was approved and an application for ethics approval was prepared for submission to the university's ethics committee (i.e. an institutional review board or IRB). Since no real people were going to be involved in conducting the research, the researchers believed that the research project was likely to be approved as it presented only low risk, according to the ethics committee guidelines. (1) No personal data was to be gathered by the researchers from human subjects. (2) There were no invasive procedures to be carried out on human or animal subjects. (3) Human evaluators who would participate in the evaluation of the artefact would simply judge the usefulness of the results for their utility for their purposes, but this would not subject the evaluators to any stress or discomfort. From the perspective of social science and behavioural research as exemplified by this particular institutional review board, this research project presented no ethical problems.

However, one of the researchers subsequently considered that, if the artefact was created, accepted, and put into use following the research, people could potentially (and unjustly) be adversely affected, and severely so. The "disruption" of a network to prevent proliferation of WMDs might well involve the use of force, including air strikes on targets, including people and other resources. What if the artefact was misused by the eventual users (e.g. intelligence officers) and incorrect results were determined? What if there were hidden problems in the artefact itself that produced incorrect results? What if, as a consequence of errors or incorrect use, innocent people were targeted and killed or injured? Even though the research was considered low risk in its limited context, an artefact produced through DSR could at a later stage be placed in the hands of others to use or misuse, perhaps with disastrous consequences. The question then became "Where do the ethical responsibilities of the DSR researchers end?" Was it enough to correctly develop an artefact that could correctly detect a weak point in a network working toward WMDs? Or should one consider consequences beyond that? In this case, the researchers decided to ask the ethics committee by writing the above concerns into the "any other ethical issues" part of the application, and after considering a kind of 
question (i.e. a DSR-related one) it had never been asked before, the ethics committee decided not to grant ethics approval for the research project.

In this case, the research did not go ahead. Had it gone ahead, one has difficulty seeing how the interests of the innocents that might become 'collateral damage' could ever have been protected in this research. The correct decision may well have been the one taken, i.e. not to proceed with the research.

However, the answer here is not that easy. What if a terrorist gets access to a WMD precisely because the research was not carried out and the artefact was not available? What if hundreds or thousands of people are killed because of that decision? There are no easy answers to these questions.

What the case does show is that two of our suggested principles are essential. First, principle 6 concerning the quality of the artefact is important. Had the research gone ahead, an artefact that was always correct and also that minimised or eliminated the possibility of misuse would be essential. Second, principle 1, that the interests of the public, especially in this case innocent bystanders or people potentially misidentified as being part of the network, would need to be witnessed for, is important. Without this principle, the safety critical nature of the artefact being developed and its potentially disastrous consequences could have been overlooked or ignored.

Principles 1 and 6 are unique to DSR, because the new artefacts that are developed in DSR potentially have an impact on (parts of) the public at large. Ethical principles need to be in place to ensure that that impact is for the good of all people and does no harm, or at least, that the good far outweighs the (perhaps unavoidable) harm.

\section{Discussion and Conclusions}

The purpose of this paper is to initiate a dialog and debate about the need for ethical principles in design science research in information systems. To this end we have suggested a set of ethical principles for DSR in IS. We would like to emphasize once again the tentative nature of our principles: they are simply a suggested set of ethical principles, the intention being to start a debate on this important subject.

We freely acknowledge that there are many other ethical frameworks that we could have used, such as those based on Aristotle's ethics, Kant's categorical imperative, or postmodern ethical philosophers such as Mackie or Lyotard. However our hope is that IS researchers will build upon, refine and modify the ones we have provided as needed. Our suggested set of principles are a stake in the ground for design science research. We believe it is imperative that all design science researchers should consider the ethical dimensions of their work and the ones we have proposed are directly relevant to the conduct of research involving the design of IT by, with, and for people.

Our suggested principles are not intended to be overly prescriptive. They allow a degree of freedom on the part of the researcher to decide which principles might be more applicable in a given situation than others. We also caution that there are ethical dilemmas. Sometimes it is not easy to decide how a particular principle should be interpreted, or if two principles conflict, which principle should have priority. However, we believe it is better for design science researchers to at least thoughtfully consider these ethical dilemmas, than to not consider ethics at all. 
One contribution of our paper has been to show that the ethical principles that apply to social science and behavioural research (the paradigm that has dominated IS research until recently) are insufficient for DSR; they are insufficient because they ignore the potential of an artefact to affect the public at a later date. Following the lead of the ACM and other computing and engineering societies, we believe that the public interest should take priority over other ethical considerations. A design science researcher in IS should consider the public interest over and above his or her responsibilities to the user or organization involved in the research project. This suggests to us that a body such as the Association for Information Systems might want to reconsider its current ethical guidelines.

We conclude by asking all design science researchers in IS a question: do we want to have a reputation for integrity and competence, and for the thoughtful application of IT in organisations? Or do we want to ignore ethics, as some members of the accounting profession did, and risk having our scholarly reputation harmed? We need to begin this debate now. Our proposal is that design science researchers in IS should first of all attempt to agree on a set of ethical guidelines for the field (the ethical principles in this paper being just a suggestion), and secondly, all design science researchers should be encouraged to consider the application of a set of ethical principles in their research work. We hope our paper helps to stimulate a discussion and debate on this important subject.

\section{References}

[1] A.R. Hevner, S.T. March, J. Park, S. Ram, Design Science in Information Systems Research, MIS Quarterly 28 (1), 2004, pp. 75-105.

[2] S.T. March, G.F. Smith, Design and natural science research on information technology, Decision Support Systems 15 (4), 1995, pp. 251-266.

[3] V. Vaishnavi, W. Kuechler, Design Research in Information Systems, in, IS World, 2004. [4] J.R. Venable, R. Baskerville, Eating Our Own Cooking: Toward a More Rigorous Design Science of Research Methods, Electronic Journal of Business Research Methods 10 (2), 2012, pp. 141-153.

[5] J. Pries-Heje, J.R. Venable, D. Bunker, N.L. Russo, J.I. DeGross, Proceedings of the IFIP WG 8.2 + 8.6 Joint International Working Conference on Human Benefit through the Diffusion of IS Design Science Research, in: AICT, Springer, Berlin, Germany, 2010.

[6] J.R. Venable, J. Pries-Heje, D. Bunker, N.L. Russo, Design and Diffusion of Systems for Human Benefit: Toward More Humanistic Realisation of Information Systems in Society, Information Technology \& People 24 (3), 2011, pp. 208-216.

[7] M. Bilandzic, J.R. Venable, Towards Participatory Action Design Research: Adapting Action Research and Design Science Research Methods for Urban Informatics, Journal of Community Informatics 7 (3), 2011, Article 786.

[8] K. Peffers, T. Tuunanen, M.A. Rothenberger, S. Chatterjee, A design science research methodology for Information Systems Research, J Manage Inform Syst 24 (3), 2007, pp. 45 77.

[9] J.R. Venable, A Framework for Design Science Research Activities, in: 2006 Information Resource Management Association Conference Information Resource Management Association, Washington, DC, USA, 2006.

[10] M. Sein, O. Henfridsson, S. Purao, M. Rossi, R. Lindgren, Action design research, MIS Quarterly 35 (2), 2011, pp. 37-56.

[11] R. Baskerville, J. Pries-Heje, J.R. Venable, Soft Design Science Methodology, in: S. Purao, K. Lyytinen, I.-Y. Song (Eds.) 4th International Conference on Design Science 
Research in Information Systems and Technology (DESRIST 2009), Philadelphia, Pennsylvania, USA, 2009.

[12] J. Iivari, J.R. Venable, Action Research and Design Science Research - Seemingly similar but decisively dissimilar, in: 2009 European Conference on Information Systems (ECIS 2009), Verona, Italy, 2009, pp. 2711-2723.

[13] S. Gregor, The Nature of Theory in Information Systems, MIS Quarterly 30 (3), 2006, pp. 611-642.

[14] S. Gregor, D. Jones, The Anatomy of a Design Theory, Journal of the Association for Information Systems 8 (5), 2007, pp. 312-335.

[15] J.G. Walls, G.R. Widmeyer, O.A. El Sawy, Building an information system design theory for vigilant EIS, Information Systems Research 3 (1), 1992, pp. 36-59.

[16] J.G. Walls, G.R. Widmeyer, O.A. El Sawy, Assessing Information System Design Theory in Perspective: How Useful Was Our 1992 Initial Rendition?, JITTA : Journal of Information Technology Theory and Application 6 (2), 2004, pp. 43-58.

[17] J.R. Venable, The Role of Theory and Theorising in Design Science Research, in: A.R. Hevner, S. Chatterjee (Eds.) First International Conference on Design Science Research in Information Systems and Technology (DESRIST 2006), Claremont, CA, USA, 2006.

[18] J.R. Venable, Rethinking Design Theory in Information Systems, in: J. vom Brocke, S.

Ram, M. Rossi (Eds.) 8th International Conference on Design Science Research in Information Systems and Technology (DESRIST 2013), Springer, Helsinki, Finland, 2013.

[19] R. Baskerville, J. Pries-Heje, Explanatory Design Theory, Business \& Information Systems Engineering 2010 (5), 2010, pp. 271-282.

[20] C. Soanes, A. Stevenson, Concise Oxford English Dictionary, in, Oxford University Press, Oxford, 2004.

[21] R.O. Mason, Four Ethical Issues of the Information Age, MIS Quarterly 10 (1), 1986, pp. 5-12.

[22] G. Gloeckler, The Best Undergraduate B-Schools for Ethics, in, Bloomberg Businessweek, 2013.

[23] Academy of Management, Revised Code of Ethics, in, 2008.

[24] Association for Information Systems, Code of Research Conduct, in, 2013.

[25] American Anthropological Association, Statement on Ethics: Principles of Professional

Responsibilities, in, American Anthropological Association, Arlington, VA, USA, 2012.

[26] ACM/IEEE-CS Joint Task Force on Software Engineering Ethics and Professional

Practice (SEEPP), Software Engineering Code of Ethics and Professional Practice, in,

Association for Computing Machinery (ACM), http://www.acm.org/about/se-code, 1999.

[27] G.D. Carnegie, C.J. Napier, Traditional Accountants and Business Professionals:

Portraying the Accounting Profession after Enron, Accounting, Organizations and Society 35 (3), 2010, pp. 360-376.

[28] M.D. Myers, H.K. Klein, A Set of Principles for Conducting Critical Research in Information Systems, MIS Quarterly 35 (1), 2011, pp. 17-36.

[29] J.M. Heusinger, Challenges of Critical and Emancipatory Design Science Research The Design of ' Possible Worlds' as Response, in: Proceedings of the 15th International Conference on Enterprise Information Systems, 2013, pp. 228-233.

[30] K.A. Siek, What are our responsibilities when designing sociotechnical health interventions?, Interactions 18, 2011, pp. 20-23.

[31] M.D. Myers, L. Miller, Ethical Dilemmas in the Use of Information Technology: An

Aristotelian Perspective, Ethics and Behavior 6 (2), 1996, pp. 153-160.

[32] J.R. Venable, Identifying and Addressing Stakeholder Interests in Design Science

Research: An Analysis Using Critical Systems Heuristics, in: IFIP WG 8.2 Working 
Conference on The role of IS in leveraging the intelligence and creativity of SME's (CreativeSME), Springer, Guimarães, Portugal, 2009, pp. 93-112.

[33] M.D. Myers, Qualitative Research in Business \& Management, 2nd ed., Sage Publications, London, 2013.

[34] B. Jackson, Fieldwork, University of Illinois Press, Urbana and Chicago, 1987.

[35] D. Gotterbarn, K. Miller, S. Rogerson, Software Engineering Code of Ethics is Approved, Communications of the ACM 42 (10), 1999, pp. 102-107.

[36] B.J. Oates, Researching Information Systems and Computing, Sage Publications, London, 2006.

[37] G. Payne, J. Payne, Key Concepts in Social Research, Sage Publications, London, 2004. [38] W. Ulrich, Critical Heuristics of Social Systems Design, European Journal of Operational Research 31, 1987, pp. 276-283.

[39] J.R. Venable, J. Pries-Heje, R. Baskerville, A Comprehensive Framework for Evaluation in Design Science Research, 7th International Conference on Design Science Research in Information Systems and Technology (DESRIST 2012), 2012.

[40] H. Peiris, H. Armstrong, J.R. Venable, Using Meta-Networks to Identify Key Intervention Points in Nuclear WMD Development, in: IEEE Network Science Workshop 2011, West Point, NY, USA, 2011. 